\title{
Predictors for additional anterior cruciate ligament reconstruction: data from the Swedish national ACL register.
}

Anne Fältström, Martin Hägglund, Henrik Magnusson, Magnus Forssblad and J oanna Kvist

The self-archived postprint version of this journal article is available at Linköping University Institutional Repository (DiVA):

http:// urn.kb.se/ resolve?urn=urn:nbn:se:liu:diva-115943

N.B.: When citing this work, cite the original publication.

The original publication is available at www.springerlink.com:

Fältström, A., Hägglund, M., Magnusson, H., Forssblad, M., Kvist, J ., (2016),

Predictors for additional anterior cruciate ligament reconstruction: data from the Swedish national ACL register., Knee Surgery, Sports Traumatology, Arthroscopy, 24(3), 885-894. https:/ / doi.org/ 10.1007/ s00167-014-3406-6

Original publication available at:

https:/ / doi.org/ 10.1007/ s00167-014-3406-6

Copyright: Springer Verlag (Germany)

http:// www.springerlink.com/ ?MUD=MP 
Title: Predictors for additional anterior cruciate ligament reconstruction: data from the Swedish national ACL register

\begin{abstract}
Purpose To identify predictors for additional anterior cruciate ligament (ACL) reconstruction.

Methods Patients from the Swedish national ACL register who underwent ACL reconstruction between January 2005 and February 2013 (follow-up duration 6-104 months) were included. Cox regression analyses included the following independent variables regarding primary injury: age, sex, time between injury and primary ACL reconstruction, activity at primary injury, concomitant injuries, injury side, graft type, and pre-surgery KOOS and EQ-5D scores.
\end{abstract}

Results Among ACL reconstruction procedures, 93\% involved hamstring tendon (HT) autografts. Graft type did not predict additional ACL reconstruction. Final regression models only included patients with HT autograft $(n=$ 20,824). Of these, 702 had revision and 591 contralateral ACL reconstructions. The 5-year postoperative rates of revision and contralateral ACL reconstruction were 4.3\% and 3.8\%, respectively. Significant predictors for additional ACL reconstruction were age (4-fold increased rate for < 16-year-old patients versus > 35-year-old patients), time between injury and primary surgery (2- to 3-fold increased rate for ACL reconstruction within 090 days versus $>365$ days), and playing football at primary injury.

Conclusions This study identified younger age, having ACL reconstruction early after the primary injury, and incurring the primary injury while playing football as the main predictors for revision and contralateral ACL reconstruction. This suggests that the rate of additional ACL reconstruction is increased in a selected group of young patients aiming to return to strenuous sports after primary surgery and should be taken into consideration when discussing primary ACL reconstruction, return to sports, and during post-surgery rehabilitation.

Level of evidence: Level II.

Keywords ACL reconstruction registry · Contralateral · Cox regression analyses $\cdot$ Ligament registry $\cdot$ Revision • Subsequent injury 
Title: Predictors for additional anterior cruciate ligament reconstruction: data from the Swedish national ACL register

\section{Introduction}

In the general Swedish population aged 10-64 years, anterior cruciate ligament (ACL) injury occurs with an incidence of approximately 81/100 000 people/year [12]. Among patients who experience recurrent swelling and giving way and who participate in high-demand activities, ACL reconstruction (ACLR) is considered the standard care after injury [42]. Databases, such as the Kaiser Permanente Anterior Cruciate Ligament Reconstruction Registry [27] and the national ACL registers in Scandinavia [2,11,15,24], have been created with the overall goals of identifying factors related to patient outcomes and improving care of individuals with ACL injuries through improved feedback to surgeons [10].

ACL injury carries a high recurrence rate. Paterno et al. [29] investigated a population of active young individuals (10-25 years of age) who resumed cutting and pivoting activities after an ACLR, and reported that approximately 25\% sustained a new ACL injury within one year. Compared with a knee-healthy person, a patient with an ACL-reconstructed knee has a greater risk of sustaining a new ACL injury in either knee [30]. The literature suggests that risk factors for sustaining an ipsi- and contralateral ACL injury include return to high activity level [5,33,44], young age at first injury [5,11,19,26,33,43,44], impaired postural control, and reduced hip and knee control during a landing task [30]. Additionally, use of allograft is a risk factor for graft rupture [5,19,26,43]. Inconsistent evidence exists to support other proposed risk factors, including sex [6,18,23,39,41], family history of ACL injury [6,39,44], notch width [40], graft type [6,23,39], and early return to full activity after ACLR [22,41].

Many patients who suffer a new ACL injury also undergo an additional ACLR. ACL registers show a revision rate of $3.3-7.7 \%$ for the primary ACLR after 5-6 years of follow-up [2,17,21,24,27,42], and a rate of $3.8-6.5 \%$ for ACLR in the contralateral knee $[2,17,21,42]$. In the literature, identified risk factors for additional ACLR (revision and contralateral) include primary ACLR at an age younger than 20 years $[21,25,31,43]$ and ACLR performed by lower-volume surgeons or lower-volume hospitals [25]. Hamstring tendon (HT) autograft [31], allograft [19], and ACLR at an academic hospital are specific predictors for revision ACLR [43]. Using metal interference screw fixation of semitendinosus tendon autograft on the tibia is associated with a lower rate of revision ACLR [3]. The influences of other potential predictors for additional ACLR—such as activity at the time of primary injury, time between injury and primary ACLR, presence of any concomitant injuries, and injury 
side — have not been well studied in large cohorts with multivariable analyses. Understanding predictors for new subsequent ACL injury and additional ACLR is important to be able to prevent such reoccurrences. Thus, clinicians should take such predictors into account when informing and advising patients prior to primary ACLR, and in the post-surgery rehabilitation and return-to-sports decision.

The present study aimed to identify predictors for additional ACLR in the ipsi- or contralateral knee following primary ACLR in a large cohort.

\section{Materials and methods}

\section{The Swedish national ACL register}

Data were extracted from the Swedish national ACL register—a database that has used web-based protocols to record ACLR since January 2005 (www.aclregister.nu). Several reports from this cohort have previously been published $[1-4,9,21]$. It is estimated that more than $90 \%$ of all ACLR in Sweden are registered, with data entered by both the surgeon (surgeon data) and the patients (patient-reported outcome measures, PROM). The PROM of the register consists of two questionnaires, the Knee Injury and Osteoarthritis Outcome score (KOOS) [37] and EQ-5D [34]. The KOOS evaluates knee-related problems on five subscales: pain, symptoms, activities in daily living (ADL), function in sports and recreation (Sport/Rec), and knee-related quality of life (QoL). For each subscale, a subscore is calculated, ranging from 0 (worst) to100 (best) [36,37]. The subscales Sport/Rec and QoL are the most responsive for patients after an ACLR [16]. The two-part EQ-5D assesses general health-related QoL [34]. The first part is the EQ-5D descriptive system, which includes five dimensions: mobility, self-care, usual activities, pain/discomfort, and anxiety/depression. The responses are used to calculate index values ranging from $<0$ (worst) to 1 (best). The second part is the EQ VAS, which records self-rated health on a vertical VAS (0-100) with 0 indicating the "worst imaginable health state" and 100 indicating the "best imaginable health state” (100). The suggested minimal clinically important differences for these instruments are 8-10 points for the KOOS [36], 0.08 for the UK EQ-5D index, and 8-12 for the EQ-5D VAS [32].

\section{Study sample}

All patients registered in the Swedish national ACL register who underwent primary ACLR between the $1^{\text {st }}$ of January 2005 and the $27^{\text {th }}$ of February 2013 were considered for inclusion. Exclusion criteria were previous ACLR to the ipsi- or contralateral knee; missing information about used graft type; associated posterior cruciate 
ligament injury; injury to the posterior lateral corner; and any fracture, nerve injuries, osteotomies, or surgically treated injury to either the medial or lateral collateral ligament. The total study sample included data from approximately 320 surgeons in 76 orthopedic clinics (public health care system and private).

\section{Outcome and predictor variables}

Patient outcomes were followed until the $27^{\text {th }}$ of August 2013, allowing a minimum of 6 months follow-up (range, 6-104 months). Outcome variables included additional revision or contralateral ACLR. Patients were followed up to the first additional revision ACLR or contralateral ACLR, or up to the end of the study. The analyses included both patient and surgical factors as predictors. Patient factors were age at primary ACLR $(<16$, 16-25, 26-35, or $>35$ years), sex, primary injury to the right or left knee, activity at the time of primary injury (“football”, "other contact ball sports”, “other sports/recreation”, and "other causes”. The category “other contact ball sports” included handball, basketball, floor ball, American football, and rugby. "Other sports/recreation” comprised ice hockey, bandy, volleyball, cross-country skiing, alpine/telemark skiing, snowboard, racquet sports, martial arts, gymnastics, dance, enduro/motocross, other leisure sports, and recreational activities. ”Other causes” included work, traffic, and other causes), and pre-operative KOOS and EQ-5D scores. Surgical factors included time between injury and primary ACLR (0-90 days, 91-365 days, or >365 days) [20], presence of any concomitant injuries (lesion of the medial or lateral meniscus or cartilage as registered at the primary ACLR), and graft type (bone-patellar-tendon bone graft (BPTB), HT autograft, or other grafts).

\section{Ethical approval}

The study was approved by the Regional Ethical Committee at Linköping University (Dnr 2013/321-31) and by the Swedish National ACL Register board.

\section{Statistical methods}

All statistical analyses were performed using IBM SPSS Statistics for Windows (Version 21.0. Armonk, NY: IBM Corp.). Mean and standard deviation (SD) or median and interquartile range (IQR) were calculated for descriptive statistics. Multivariable Cox proportional hazards regression models were used to estimate associations between predictors (i.e., age, sex, injury side, activity performed at the time of first ACL injury, time between ACL injury to primary ACLR, and presence of any concomitant injuries) and the occurrence of additional ACLR (revision or contralateral) during the follow-up period. This analysis allows us to consider the 
time to additional ACLR as an important factor and differences in follow-up times between patients are taken into account in the survival analyses. Time was recorded in days. The final models were determined using a backward procedure starting with the inclusion of all predictors, and performing stepwise deletion of the variables with the highest $P$ values until only significant variables remained. Several items were analyzed separately using simple Cox regression models, including preoperative KOOS and EQ-5D due to low response rates, and graft type due to a skewed distribution. Hazard ratios (HRs) with 95\% confidence intervals (CIs) and $P$ values were included in the models. The significance level was set at $P<0.05$.

\section{Results}

As of $27^{\text {th }}$ of August 2013, a total of 22,429 patients meeting the inclusion criteria were registered with surgeon data, among whom 20,824 (93\%) had surgery with HT autograft, 1,429 (6\%) with BPTB graft, and 174 (1\%) with other grafts (including 37 allografts). The rate of additional ACLR did not differ according to graft type. For revision ACLR, BPTB graft showed an HR of 0.86 (95\% CI, 0.65-1.13; n.s.) and other grafts showed an HR of 1.44 (95\% CI, 0.65-3.22; n.s.), with HT autograft as reference. For contralateral ACLR, BPTB graft showed an HR of 0.92 (95\% CI, 0.69-1.21; n.s.) and other grafts showed an HR of 0.91 (95\% CI, 0.30-2.91; n.s.) with HT autograft as reference. To obtain a more homogeneous cohort, subsequent analyses included only patients with HT autograft ( $\mathrm{n}=20,824)$, of whom 702 underwent revision ACLR and 591 contralateral ACLR during follow-up (Table 1).

There were low response rates for KOOS (68-69\%) and EQ-5D (60-63\%) and, therefore, these parameters were not included in the final Cox regression multivariable model. Simple Cox regression analyses showed statistically significant predictors for revision ACLR for the KOOS symptoms subscale, EQ-5D index and EQ VAS, and for contralateral ACLR for the KOOS subscales pain, ADL, Sport/Rec, and QoL (Table 2).

Table 3 presents the numbers of patients who had additional ACLR during each year of follow-up. A majority of the revision ACLR (58\%) occurred within the first two years postoperatively, and 51\% of contralateral ACLR occurred between the first and third years postoperatively. Fig. 1 presents cumulative proportion events at end of interval for revision and contralateral ACLR over the follow-up period.

\section{Predictors of revision and contralateral ACLR in the multivariable model}

Table 4 presents the final Cox regression models with variables associated with additional ACLR, which included 18,746 primary ACLR for the outcome revision ACLR (648 events), and 18,761 primary ACLR for the 
outcome contralateral ACLR (552 events). The most commonly missing data were relating to the variable days between injury and primary ACLR due to a missing injury date.

Among the patient factors in the multivariable Cox model, significant predictors for revision ACLR included age and activity at injury (Table 4). Sex and side of primary injury (right or left knee) were not significant predictors (n.s.). Time between injury and ACLR was the only significant surgical factor to predict revision ACLR. Concomitant intra-articular injuries was not significant (n.s.).

Among the patient factors in the multivariable Cox model, significant predictors for contralateral ACLR were age and activity at injury (Table 4), while sex and side of primary injury (right or left knee) were not significant (n.s.). Among surgical factors, time between injury and ACLR predicted contralateral ACLR, while presence of concomitant intra-articular injuries was not significant (n.s.).

\section{Discussion}

The main findings of this study were that younger age, undergoing primary ACLR early after injury, and incurring ACL injury while playing football were predictors of additional ACLR to both the ipsi- and contralateral knee. This suggests an increased rate of additional ACLR within a selected group of young patients who are most likely aiming to return to strenuous sports after primary ACLR.

The present study included the largest published cohort of ACLR patients to date, with nearly 21,000 patients and a median follow-up of 4 years. The determined 5-year rates of revision (4.3\%) and contralateral (3.8\%) ACLR were similar to those reported in other register studies: 3.3-7.7\% for both revision and contralateral ACLR with follow-up times of approximately 5 years [2,17,21,24,27,42]. Most additional ACLR occurred within the first three years postoperatively, with almost 3 out of 5 revision ACLR procedures performed within the first two years. This high early recurrence rate could be related to many factors. In particular, it can be speculated that insufficient rehabilitation, premature return to sports, technical failure at the primary ACLR, and biological issues are contributing factors. Healthcare professionals should be aware of this increased rate of additional ACLR, especially revision ACLR, during the first two years after primary ACLR. Our present finding that young age predicted a subsequent ACLR is in line with previous reports $[25,26,43]$. Young age ( $<20$ years) has been previously found to be a predictor for subsequent ACLR, as well as for repeated knee surgeries after ACLR [17]. Hettrich et al. [17] investigated the Multicenter Orthopaedic Outcomes Network (MOON) cohort, and found that $18.9 \%$ had additional surgery to the ipsilateral knee and $10.2 \%$ to the contralateral knee at 6-year follow-up. Younger people are expected to have a higher activity level, 
especially in contact sports [24,44]. Return to strenuous sports that include sidestepping, pivoting, and jumping is a predictor for revision ACLR [5], and also for graft rupture by a factor of 3.9 and for contralateral rupture by a factor of 5 [44]. Fältström et al. [13] have previously shown that patients with bilateral ACL injuries had a high activity level before their second injury, which is in agreement with these findings. In the present study, no information was available regarding the patients' activity level or return to sports.

Another predictor for additional ACLR was the activity performed when sustaining the primary ACL injury. Compared with other activities, football was associated with an increased rate of additional ACLR. It should be stressed that the available activity data in the current study only represents the activity performed at the occurrence of the primary injury, and that no information was available regarding regular sports participation before or after the primary ACLR. Nonetheless, it is plausible that these patients represent an active subgroup of the cohort to a high degree. A previous study from the Swedish ACL register showed that young females who injured their ACL while playing football have an increased rate of subsequent revision or contralateral ACLR [2]. On the other hand, data from the Danish ACL register [24] showed that the cause of primary injury (sports/no sports) did not influence the risk for ACL revision.

Compared with delayed ( $>12$ months) ACLR, early ACLR ( $<3$ months from injury to surgery) [20] was a predictor for additional ACLR in the present study. In Sweden, the median time for ACLR after primary injury is more than 8 months [21], and patients most often undergo physiotherapist-supervised rehabilitation before it is decided whether to perform ACLR. It can be argued that the predictor is not the time between injury and surgery per se, but rather that early ACLR is most often performed in a selected sample of highly active young patients who desire a rapid return to strenuous sports. In a systematic review, De Valk et al. [8] also showed that patients with an early ACLR ( $<3$ months) had higher activity levels after ACLR.

The use of BPTB graft is decreasing, with 98\% of the ACLR in 2012 in Sweden performed using hamstring autograft [21] (www.aclregister.nu). While previous studies have found that HT grafts $[26,31,35]$ and allografts $[26,43]$ increase the rate of revision ACLR, graft type was not a predictor for additional ACLR in this study. A Cochrane review from 2011 reported no difference in re-rupture risk between BPTB and HT graft [28]. At present, only a selected group of surgeons and a few clinics in Sweden still use BPTB graft and, therefore, it is possible that factors other than the graft type itself influence the risk of revision ACLR. The current study included very few ACLR with allograft (37 patients), and the sample was insufficiently sized to compare the rate of additional ACLR in this group against other grafts. Andernord et al. [3] recently investigated the Swedish National ACL register, and reported that graft selection, graft width, use of a single-bundle or double-bundle 
technique, femoral graft fixation, the injury-to-surgery interval, and meniscus injury were not predictors of early revision ( $\leq 2$ years) ACLR.

The present results showed a small, but statistically significant association between preoperative KOOS and EQ-5D scores and the rate of additional ACLR. However, the direction of this association between preoperative PROM and additional ACLR varied. The reasons for this variation remain unclear. It is possible that preoperative PROM could reflect the outcome of the preoperative rehabilitation. Granan et al. [14] reported that every 10-point reduction in the KOOS QoL measured at 2 years postoperatively is associated with a 34\% higher risk for later revision ACLR. Further analysis of PROM as a predictor for additional ACLR is required. Concomitant injuries, such as meniscus and cartilage injuries, were not a predictor for additional ACLR in the present study. This is in line with the findings of Wasserstein et al. [43]; however, Lyman et al. [25] reported that concomitant meniscectomy or other knee surgery were predictors of subsequent ACLR. In the present study, injury side (right or left knee) was not a predictor for additional ACLR. To our knowledge, this factor has not previously been investigated in large register studies. Brophy et al. [7] found that football players who underwent ACLR on their nondominant limb had a significantly higher rate of future contralateral ACLR. As the ACL register does not report limb dominance and represents a diversity of sports, it is difficult to compare this information with previous studies. The current study also showed that the rate of additional ACLR was not associated with sex, which is in agreement with previous studies analyzing subsequent ACL injury $[38,39,44,45]$ or additional ACLR $[25,38,43]$.

The major strength of the present study is the large patient population that makes the results highly generalizable to individuals with ACLR with hamstring tendon autograft, at least within Sweden. In addition to those already mentioned, several limitations to using registry data should be acknowledged. First, the utilized registry did not include data on several potentially important predictors for subsequent ACLR—e.g., return to sport and activity level, rehabilitation factors, and injury mechanism. Second, there were low response rates on the preoperative KOOS and EQ-5D questionnaires, and thus these variables could not be included in the final model. Furthermore, it would have been valuable to also analyze KOOS and EQ-5D postoperatively, as these could arguably be more important predictors for additional ACLR; however, such data were not included due to the even lower response rates (41-51\%). Third, it should be stressed that the true rate of new ACL injury to the ipsi- or contralateral knee is unknown, since only additional ACLR are reported in the register, not nonsurgically treated ACL ruptures. In this context, it should also be acknowledged that while a second ACL injury is unquestionably a negative outcome, undergoing an additional ACLR could in fact represent a favorable 
outcome for some patients. It is plausible that young and active patients are more frequently offered additional ACLR, while older patients who are active at a recreational level may instead be recommended non-surgical treatment. Such patient selection for surgery could be one explanation for why younger and more active patients had an increased rate of additional ACLR in the present study. Fourth, a minimum follow-up of 6 months was selected because very few patients are expected to undergo additional ACLR within less than 6 months. This choice may have resulted in the exclusion of some patients with shorter follow-up who would eventually undergo additional ACLR. Finally, although the register is believed to include more than 90\% of all ACL surgeries in Sweden, some patients could have been lost to follow-up for reasons such as moving out of the country (young people tend to move more often than older individuals) or death, and it is possible that a second ACLR was not reported in the register for some patients. Therefore, similar to in other studies, the rate of subsequent ACLR may have been underestimated [25].

\section{Conclusion}

This study identified younger age, having ACLR early after the primary injury, and incurring the primary injury while playing football as the main predictors for revision and contralateral ACLR. This suggests an increased rate of additional ACLR in a selected group of young patients who likely desire a rapid return to strenuous sports after primary surgery. This information should be used when discussing expectations and risks of new injury with the patient prior to the ACLR. This finding should also be taken into consideration during post-surgery rehabilitation and when discussing return to sports/activity with these patients.

\section{Acknowledgments} The study was financially supported by Futurum—-the academy for healthcare, County Council, Jönköping, the Faculty of Health Sciences at Linköping University, and the Swedish National Centre for Research in Sports (CIF).

\section{Ethical standards}

The study has been approved by the appropriate ethics committee and was performed in accordance with the ethical standards laid down in the 1964 Declaration of Helsinki. Participation in the Swedish national register is voluntary for surgeons and patients, and thus no written consent is necessary. All data are unidentifiable patient data. 
243 The authors declare that they have no conflict of interest.

\section{References}

1. Ageberg E, Forssblad M, Herbertsson P, Roos EM (2010) Sex differences in patient-reported outcomes after anterior cruciate ligament reconstruction: data from the Swedish knee ligament register. Am J Sports Med 38 (7):1334-1342.

2. Ahlden M, Samuelsson K, Sernert N, Forssblad M, Karlsson J, Kartus J (2012) The Swedish National Anterior Cruciate Ligament Register: a report on baseline variables and outcomes of surgery for almost 18,000 patients. Am J Sports Med 40 (10):2230-2235.

3. Andernord D, Bjornsson H, Petzold M, Eriksson BI, Forssblad M, Karlsson J, Samuelsson K (2014) Surgical Predictors of Early Revision Surgery After Anterior Cruciate Ligament Reconstruction: Results From the Swedish National Knee Ligament Register on 13,102 Patients. Am J Sports Med 42 (7):1574-1582.

4. Barenius B, Forssblad M, Engstrom B, Eriksson K (2013) Functional recovery after anterior cruciate ligament reconstruction, a study of health-related quality of life based on the Swedish National Knee Ligament Register. Knee Surg Sports Traumatol Arthrosc 21 (4):914-927.

5. Borchers JR, Pedroza A, Kaeding C (2009) Activity level and graft type as risk factors for anterior cruciate ligament graft failure: a case-control study. Am J Sports Med 37 (12):2362-2367.

6. Bourke HE, Salmon LJ, Waller A, Patterson V, Pinczewski LA (2012) Survival of the anterior cruciate ligament graft and the contralateral ACL at a minimum of 15 years. Am J Sports Med 40 (9):19851992.

7. Brophy RH, Schmitz L, Wright RW, Dunn WR, Parker RD, Andrish JT, McCarty EC, Spindler KP (2012) Return to play and future ACL injury risk after ACL reconstruction in soccer athletes from the Multicenter Orthopaedic Outcomes Network (MOON) group. Am J Sports Med 40 (11):2517-2522.

8. de Valk EJ, Moen MH, Winters M, Bakker EW, Tamminga R, van der Hoeven H (2013) Preoperative patient and injury factors of successful rehabilitation after anterior cruciate ligament reconstruction with singlebundle techniques. Arthroscopy 29 (11):1879-1895.

9. Desai N, Bjornsson H, Samuelsson K, Karlsson J, Forssblad M (2014) Outcomes after ACL reconstruction with focus on older patients: results from The Swedish National Anterior Cruciate Ligament Register. Knee Surg Sports Traumatol Arthrosc 22 (2):379-386.

10. Engebretsen L, Forssblad M (2009) Why knee ligament registries are important. Knee Surg Sports Traumatol Arthrosc 17 (2):115-116.

11. Forssblad M The Swedish national knee ligament register. Swedish national ACL database homepage. www.aclregister.nu. Accessed 2014-03-19

12. Frobell RB, Lohmander LS, Roos HP (2007) Acute rotational trauma to the knee: poor agreement between clinical assessment and magnetic resonance imaging findings. Scand J Med Sci Sports 17 (2):109-114.

13. Fältström A, Hägglund M, Kvist J (2013) Patient-reported knee function, quality of life, and activity level after bilateral anterior cruciate ligament injuries. Am J Sports Med 41 (12):2805-2813.

14. Granan LP, Baste V, Engebretsen L, Inacio MC (2014) Associations between inadequate knee function detected by KOOS and prospective graft failure in an anterior cruciate ligament-reconstructed knee. Knee Surg Sports Traumatol Arthrosc. doi:10.1007/s00167-014-2925-5

15. Granan LP, Inacio MC, Maletis GB, Funahashi TT, Engebretsen L (2012) Intraoperative findings and procedures in culturally and geographically different patient and surgeon populations: an anterior cruciate ligament reconstruction registry comparison between Norway and the USA. Acta Orthop 83 (6):577-582.

16. Hambly K, Griva K (2010) IKDC or KOOS: which one captures symptoms and disabilities most important to patients who have undergone initial anterior cruciate ligament reconstruction? Am J Sports Med 38 (7):1395-1404.

17. Hettrich CM, Dunn WR, Reinke EK, Group M, Spindler KP (2013) The rate of subsequent surgery and predictors after anterior cruciate ligament reconstruction: two- and 6-year follow-up results from a multicenter cohort. Am J Sports Med 41 (7):1534-1540.

18. Hui C, Salmon LJ, Kok A, Maeno S, Linklater J, Pinczewski LA (2011) Fifteen-year outcome of endoscopic anterior cruciate ligament reconstruction with patellar tendon autograft for "isolated" anterior cruciate ligament tear. Am J Sports Med 39 (1):89-98. 
19. Kaeding CC, Aros B, Pedroza A, Pifel E, Amendola A, Andrish JT, Dunn WR, Marx RG, McCarty EC, Parker RD, Wright RW, Spindler KP (2011) Allograft Versus Autograft Anterior Cruciate Ligament Reconstruction: Predictors of Failure From a MOON Prospective Longitudinal Cohort. Sports Health 3 (1):73-81.

20. Karlsson J, Kartus J, Magnusson L, Larsson J, Brandsson S, Eriksson BI (1999) Subacute versus delayed reconstruction of the anterior cruciate ligament in the competitive athlete. Knee Surg Sports Traumatol Arthrosc 7 (3):146-151.

21. Kvist J, Kartus J, Karlsson J, Forssblad M (2014) Results From the Swedish National Anterior Cruciate Ligament Register. Arthroscopy 30 (7):803-810.

22. Laboute E, Savalli L, Puig P, Trouve P, Sabot G, Monnier G, Dubroca B (2010) Analysis of return to competition and repeat rupture for 298 anterior cruciate ligament reconstructions with patellar or hamstring tendon autograft in sportspeople. Ann Phys Rehabil Med 53 (10):598-614.

23. Leys T, Salmon L, Waller A, Linklater J, Pinczewski L (2012) Clinical results and risk factors for reinjury 15 years after anterior cruciate ligament reconstruction: a prospective study of hamstring and patellar tendon grafts. Am J Sports Med 40 (3):595-605.

24. Lind M, Menhert F, Pedersen AB (2012) Incidence and outcome after revision anterior cruciate ligament reconstruction: results from the Danish registry for knee ligament reconstructions. Am J Sports Med 40 (7):1551-1557.

25. Lyman S, Koulouvaris P, Sherman S, Do H, Mandl LA, Marx RG (2009) Epidemiology of anterior cruciate ligament reconstruction: trends, readmissions, and subsequent knee surgery. J Bone Joint Surg Am 91 (10):2321-2328.

26. Maletis GB, Inacio MC, Desmond JL, Funahashi TT (2013) Reconstruction of the anterior cruciate ligament: association of graft choice with increased risk of early revision. Bone Joint J 95-B (5):623-628.

27. Maletis GB, Inacio MC, Funahashi TT (2013) Analysis of 16,192 anterior cruciate ligament reconstructions from a community-based registry. Am J Sports Med 41 (9):2090-2098.

28. Mohtadi NG, Chan DS, Dainty KN, Whelan DB (2011) Patellar tendon versus hamstring tendon autograft for anterior cruciate ligament rupture in adults. Cochrane Database Syst Rev (9):CD005960.

29. Paterno MV, Rauh MJ, Schmitt LC, Ford KR, Hewett TE (2012) Incidence of contralateral and ipsilateral anterior cruciate ligament (ACL) injury after primary ACL reconstruction and return to sport. Clin J Sport Med 22 (2):116-121.

30. Paterno MV, Schmitt LC, Ford KR, Rauh MJ, Myer GD, Huang B, Hewett TE (2010) Biomechanical measures during landing and postural stability predict second anterior cruciate ligament injury after anterior cruciate ligament reconstruction and return to sport. Am J Sports Med 38 (10):1968-1978.

31. Persson A, Fjeldsgaard K, Gjertsen JE, Kjellsen AB, Engebretsen L, Hole RM, Fevang JM (2014) Increased risk of revision with hamstring tendon grafts compared with patellar tendon grafts after anterior cruciate ligament reconstruction: a study of 12,643 patients from the Norwegian Cruciate Ligament Registry, 2004-2012. Am J Sports Med 42 (2):285-291.

32. Pickard AS, Neary MP, Cella D (2007) Estimation of minimally important differences in EQ-5D utility and VAS scores in cancer. Health Qual Life Outcomes 5:70.

33. Pinczewski LA, Lyman J, Salmon LJ, Russell VJ, Roe J, Linklater J (2007) A 10-year comparison of anterior cruciate ligament reconstructions with hamstring tendon and patellar tendon autograft: a controlled, prospective trial. Am J Sports Med 35 (4):564-574.

34. Rabin R, de Charro F (2001) EQ-5D: a measure of health status from the EuroQol Group. Ann Med 33 (5):337-343.

35. Rahr-Wagner L, Thillemann TM, Pedersen AB, Lind M (2014) Comparison of hamstring tendon and patellar tendon grafts in anterior cruciate ligament reconstruction in a nationwide population-based cohort study: results from the danish registry of knee ligament reconstruction. Am J Sports Med 42 (2):278284.

36. Roos EM, Lohmander LS (2003) The Knee injury and Osteoarthritis Outcome Score (KOOS): from joint injury to osteoarthritis. Health Qual Life Outcomes 1:64.

37. Roos EM, Roos HP, Lohmander LS, Ekdahl C, Beynnon BD (1998) Knee Injury and Osteoarthritis Outcome Score (KOOS)--development of a self-administered outcome measure. J Orthop Sports Phys Ther 28 (2):88-96.

38. Ryan J, Magnussen RA, Cox CL, Hurbanek JG, Flanigan DC, Kaeding CC (2014) ACL Reconstruction: Do Outcomes Differ by Sex?: A Systematic Review. J Bone Joint Surg Am 96 (6):507-512.

39. Salmon L, Russell V, Musgrove T, Pinczewski L, Refshauge K (2005) Incidence and risk factors for graft rupture and contralateral rupture after anterior cruciate ligament reconstruction. Arthroscopy 21 (8):948-957. 
40. Shelbourne KD, Davis TJ, Klootwyk TE (1998) The relationship between intercondylar notch width of the femur and the incidence of anterior cruciate ligament tears. A prospective study. Am J Sports Med 26 (3):402-408.

41. Shelbourne KD, Gray T, Haro M (2009) Incidence of subsequent injury to either knee within 5 years after anterior cruciate ligament reconstruction with patellar tendon autograft. Am J Sports Med 37 (2):246251.

42. Spindler KP, Parker RD, Andrish JT, Kaeding CC, Wright RW, Marx RG, McCarty EC, Amendola A, Dunn WR, Huston LJ, Harrell FE, Jr., Group M (2013) Prognosis and predictors of ACL reconstructions using the MOON cohort: a model for comparative effectiveness studies. J Orthop Res 31 (1):2-9.

43. Wasserstein D, Khoshbin A, Dwyer T, Chahal J, Gandhi R, Mahomed N, Ogilvie-Harris D (2013) Risk factors for recurrent anterior cruciate ligament reconstruction: a population study in Ontario, Canada, with 5-year follow-up. Am J Sports Med 41 (9):2099-2107.

44. Webster KE, Feller JA, Leigh WB, Richmond AK (2014) Younger patients are at increased risk for graft rupture and contralateral injury after anterior cruciate ligament reconstruction. Am J Sports Med 42 (3):641-647.

45. Wright RW, Dunn WR, Amendola A, Andrish JT, Bergfeld J, Kaeding CC, Marx RG, McCarty EC, Parker RD, Wolcott M, Wolf BR, Spindler KP (2007) Risk of tearing the intact anterior cruciate ligament in the contralateral knee and rupturing the anterior cruciate ligament graft during the first 2 years after anterior cruciate ligament reconstruction: a prospective MOON cohort study. Am J Sports Med 35 (7):1131-1134. 


\section{TABLE 1}

Table 1 Characteristics of included patients with primary ACLR operated with hamstring tendon autograft

\begin{tabular}{|c|c|c|c|}
\hline \multirow[b]{2}{*}{ Variables } & \multicolumn{3}{|c|}{ Additional ACLR during follow-up } \\
\hline & $\begin{array}{l}\text { No } \\
n=19,531\end{array}$ & $\begin{array}{l}\text { Yes, } \\
\text { revision } \\
n=702\end{array}$ & $\begin{array}{l}\text { Yes, } \\
\text { contralateral } \\
n=591\end{array}$ \\
\hline Male sex, $n(\%)$ & $11,159(57.1)$ & $384(54.7)$ & 295 (49.9) \\
\hline $\begin{array}{l}\text { Follow-up time in days, } \\
\text { median (IQR) }\end{array}$ & 1,399 (1401) & 630 (629) & 800 (848) \\
\hline $\begin{array}{l}\text { Age in years (at primary ACLR), } \\
\text { mean } \pm \mathrm{SD}\end{array}$ & $27.0 \pm 9.9$ & $21.9 \pm 7.3$ & $22.3 \pm 8.4$ \\
\hline $\begin{array}{l}\text { Age group, } n(\%) \\
<16 \\
16-25 \\
26-35 \\
>35\end{array}$ & $\begin{array}{l}1,247(6.4) \\
9,070(46.4) \\
4,931(25.3) \\
4,279(21.9)\end{array}$ & $\begin{array}{l}86(12.3) \\
455(64.8) \\
111(15.8) \\
50(7.1)\end{array}$ & $\begin{array}{l}93(15.7) \\
351(59.4) \\
88(14.9) \\
59(10.0)\end{array}$ \\
\hline $\begin{array}{l}\text { Primary injury, }{ }^{\mathrm{b}} \text { n (\%) } \\
\text { right knee } \\
\text { left knee }\end{array}$ & $\begin{array}{l}10,092(51.7) \\
9,432(48.3)\end{array}$ & $\begin{array}{l}354(50.6) \\
346(49.4)\end{array}$ & $\begin{array}{l}304(51.4) \\
287(48.6)\end{array}$ \\
\hline $\begin{array}{l}\text { Days between injury and primary ACLR, } \\
n(\%) \\
0-90 \\
91-365 \\
>365\end{array}$ & $\begin{array}{l}1,994(11.3) \\
9,264(52.6) \\
6,359(36.1)\end{array}$ & $\begin{array}{l}153(23.4) \\
349(53.4) \\
151(23.1)\end{array}$ & $\begin{array}{l}96(17.4) \\
323(58.5) \\
133(24.1)\end{array}$ \\
\hline $\begin{array}{l}\text { Activity performed at primary ACL injur } \\
n(\%) \\
\text { Football } \\
\text { Other contact ball sports } \\
\text { Other sports/recreation } \\
\text { Other causes }\end{array}$ & $\begin{array}{l}8,285(42.6) \\
3,315(17.0) \\
5,819(29.9) \\
2,044(10.5)\end{array}$ & $\begin{array}{l}367(52.6) \\
117(16.8) \\
163(23.4) \\
51(7.3)\end{array}$ & $\begin{array}{l}294(49.8) \\
136(23.1) \\
129(21.9) \\
31(5.3)\end{array}$ \\
\hline $\begin{array}{l}\text { Presence of concomitant injuries at prima } \\
\text { ACLR, } n \text { (\%) } \\
\text { Meniscus injury (medial/lateral) } \\
\text { - surgically treated (\% of meniscus injuries) } \\
\text { Articular cartilage injury } \\
\text { MCL } \\
\text { LCL }\end{array}$ & $\begin{array}{l}8,300(42.5) \\
6,980(84.1) \\
5,253(26.9) \\
525(2.7) \\
117(0.6) \\
\end{array}$ & $\begin{array}{l}302(43.0) \\
238(78.8) \\
127(18.1) \\
19(2.7) \\
2(0.3) \\
\end{array}$ & $\begin{array}{l}249(42.1) \\
197(79.1) \\
136(23.0) \\
12(2.0) \\
9(1.5) \\
\end{array}$ \\
\hline $\begin{array}{l}\text { ACLR anterior cruciate ligament reconstruct } \\
\text { collateral ligament, } L C L \text { lateral collateral lige } \\
{ }^{\mathrm{a}} \text { Missing data from } 4 \text { patients, } n=19,527 \text { (n } \\
{ }^{\mathrm{b}} n=19,524 \text { (no additional ACLR), } n=700 \\
{ }^{\mathrm{c}} n=17,617 \text { (no additional ACLR), } n=653 \\
\mathrm{~d} n=19,463 \text { (no additional ACLR), } n=698\end{array}$ & $\begin{array}{l}\text { tandard deviati } \\
\text { nal ACLR) } \\
), n=591 \text { (con } \\
, n=552 \text { (con } \\
), n=590 \text { (con }\end{array}$ & Interquartil & $\overline{M C L}$ medial \\
\hline
\end{tabular}


Table 2 Pre-operative patient reported outcome measures (KOOS and EQ-5D) for primary ACLR with hamstring tendon autograft among patients who did not undergo additional ACLR $(n=19,531)$, who had revision ACLR $(n=702)$, and who had contralateral ACLR $(n=591)$

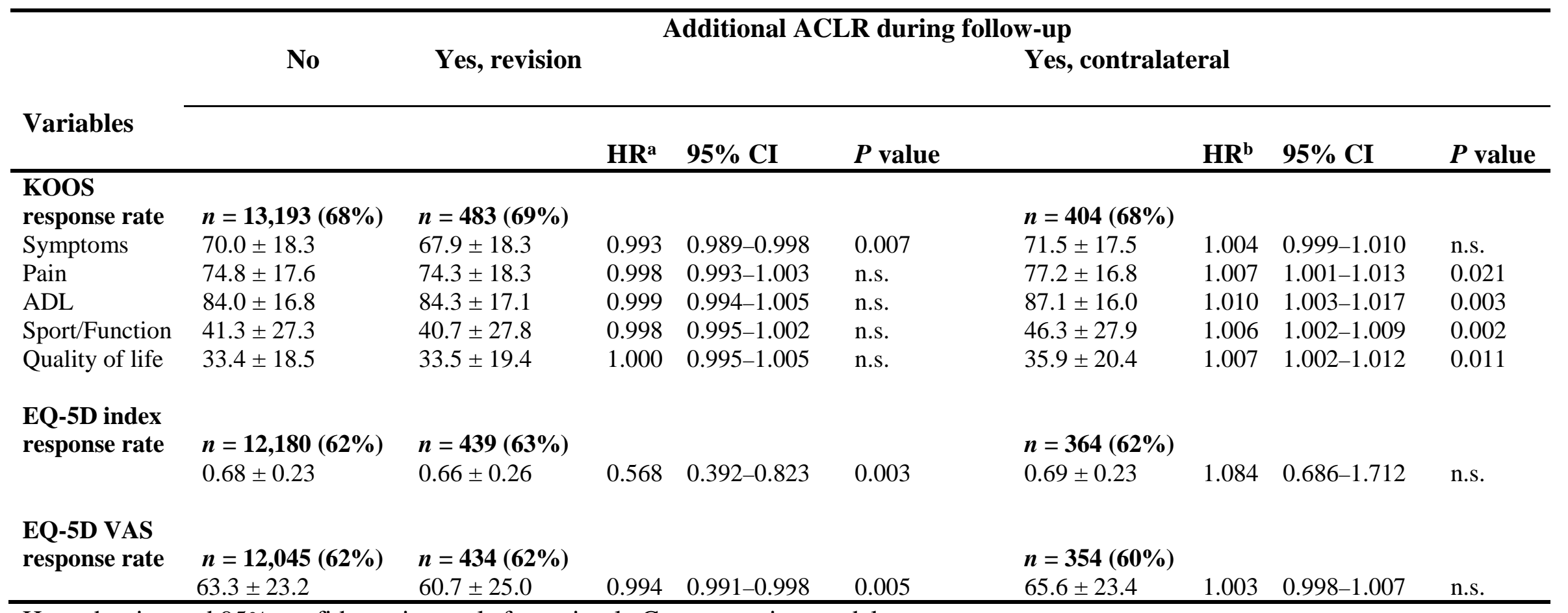

Hazard ratios and 95\% confidence intervals from simple Cox regression models

Data are presented as mean \pm SD. ACLR anterior cruciate ligament reconstruction, $S D$ standard deviation, HR Hazard ratio, CI confidence

interval, KOOS Knee injury and Osteoarthritis Outcome Score, $A D L$ activities of daily living, VAS visual analogue scale

${ }^{a}$ Hazard ratio for revision ACLR versus no revision ACLR

${ }^{\mathrm{b}}$ Hazard ratio for contralateral ACLR versus no contralateral ACLR 
Table 3 Life table of additional anterior cruciate ligament reconstruction (ACLR) in patients operated with hamstring tendon autograft

\begin{tabular}{|c|c|c|c|c|c|c|c|c|c|c|c|c|}
\hline \multirow[b]{2}{*}{ Year } & \multicolumn{6}{|c|}{ Revision ACLR ( $n=702)$} & \multicolumn{6}{|c|}{ Contralateral ACLR $(n=591)$} \\
\hline & $\begin{array}{c}\text { Entering } \\
\text { interval }^{\text {a }} \\
(n)\end{array}$ & $\begin{array}{c}\text { Censored } \\
\text { during } \\
\text { interval }^{\mathrm{b}} \\
(n)\end{array}$ & $\begin{array}{c}\text { Exposed } \\
\text { to risk } \\
(n)\end{array}$ & $\begin{array}{c}\text { Revision } \\
\text { ACLR } \\
(n)\end{array}$ & $\begin{array}{c}\text { Proportion }^{\mathbf{d}} \\
(\%)\end{array}$ & $\begin{array}{c}\text { Cumulative } \\
\text { proportion } \\
(\%)\end{array}$ & $\begin{array}{c}\text { Entering } \\
\text { interval }^{\mathbf{a}} \\
(n)\end{array}$ & $\begin{array}{c}\text { Censored } \\
\text { during } \\
\text { interval } \\
(n) \\
\end{array}$ & $\begin{array}{c}\text { Exposed } \\
\text { to } \text { risk }^{\mathrm{c}} \\
(n)\end{array}$ & $\begin{array}{c}\text { Contra- } \\
\text { lateral } \\
\text { ACLR } \\
(n) \\
\end{array}$ & $\begin{array}{c}\text { Proportion }^{\mathbf{e}} \\
(\%)\end{array}$ & $\begin{array}{c}\text { Cumulative } \\
\text { proportion } \\
(\%)\end{array}$ \\
\hline $0-1$ & 20,824 & 1,841 & $19,903.5$ & 133 & 0.7 & 0.7 & 20,824 & 1,885 & $19,881.5$ & 89 & 0.4 & 0.4 \\
\hline $1-2$ & 18,850 & 3,284 & $17,208.0$ & 276 & 1.6 & 2.3 & 18,850 & 3,393 & $17,153.5$ & 167 & 1.0 & 1.4 \\
\hline $2-3$ & 15,290 & 2,832 & $13,874.0$ & 128 & 0.9 & 3.2 & 15,290 & 2,828 & $13,876.0$ & 132 & 1.0 & 2.4 \\
\hline $3-4$ & 12,330 & 2,844 & $10,908.0$ & 76 & 0.7 & 3.8 & 12,330 & 2,844 & $10,908.0$ & 76 & 0.7 & 3.0 \\
\hline $4-5$ & 9,410 & 2,522 & $8,149.0$ & 38 & 0.5 & 4.3 & 9,410 & 2,498 & 8,161.0 & 62 & 0.8 & 3.8 \\
\hline $5-6$ & 6,850 & 2,344 & $5,678.0$ & 29 & 0.5 & 4.8 & 6,850 & 2,332 & $5,684.0$ & 41 & 0.7 & 4.5 \\
\hline $6-7$ & 4,477 & 1,997 & $3,478.5$ & 15 & 0.4 & 5.2 & 4,477 & 1,999 & $3,477.5$ & 13 & 0.4 & 4.8 \\
\hline $7-8$ & 2,465 & 1,653 & $1,638.5$ & 7 & 0.4 & 5.6 & 2,465 & 1,649 & $1,640.5$ & 11 & 0.7 & 5.5 \\
\hline$>8$ & 805 & 805 & 402.5 & 0 & 0.0 & 5.6 & 805 & 805 & 402.5 & 0 & 0.0 & 5.5 \\
\hline
\end{tabular}

${ }^{\text {a }}$ Entering interval: number of patients at start of the time interval, e.g. at 0 years, 1 year etc.

${ }^{\mathrm{b}}$ Censored during interval: number of patients whose follow-up time ended within the time interval or had a contralateral ACLR within the time interval.

${ }^{\mathrm{c}}$ Exposed to risk: number of patients who were exposed to risk for ACLR. Individuals are assumed to be censored evenly during interval, so; Exposed to risk $=$ Entering interval - (Censored during interval / 2).

${ }^{\mathrm{d}}$ Proportion revision ACLR: (number of revision ACLR / number exposed to risk) * 100.

${ }^{\text {e }}$ Proportion contralateral ACLR: (number of contralateral ACLR / number exposed to risk) * 100.

${ }^{\mathrm{f}}$ Censored during interval: number of patients whose follow-up time ended within the time interval or had a revision ACLR within the time interval. 
Table 4 Statistically significant predictors of revision and contralateral ACLR after primary ACLR from multivariable backward stepwise Cox proportional hazards regression analyses

\begin{tabular}{|c|c|c|c|c|c|c|}
\hline \multirow[b]{2}{*}{ Variables } & \multicolumn{3}{|c|}{$\begin{array}{c}\text { Revision ACLR, } \\
n=18,746\end{array}$} & \multicolumn{3}{|c|}{$\begin{array}{c}\text { Contralateral ACLR, } \\
n=18,761\end{array}$} \\
\hline & HR & 95\% CI & $\begin{array}{l}P \\
\text { Value }\end{array}$ & HR & $95 \% \mathrm{CI}$ & $\begin{array}{l}P \\
\text { Value }\end{array}$ \\
\hline \multicolumn{7}{|l|}{$\begin{array}{l}\text { Patient factors } \\
\text { Age at primary ACLR }\end{array}$} \\
\hline$<16$ & 4.26 & $2.93-6.18$ & $<0.001$ & 4.26 & $2.97-6.10$ & $<0.001$ \\
\hline $16-25$ & 3.45 & $2.51-4.74$ & $<0.001$ & 2.46 & $1.80-3.37$ & $<0.001$ \\
\hline $26-35$ & 1.61 & $1.12-2.30$ & 0.009 & 1.17 & $0.82-1.69$ & n.s. \\
\hline$>35$ Reference group & 1 & & & 1 & & \\
\hline \multicolumn{7}{|c|}{$\begin{array}{l}\text { Activity performed at primary } \\
\text { ACL injury }\end{array}$} \\
\hline Football Reference group & 1 & & & 1 & & \\
\hline Other contact ball sports & 0.78 & $0.64-0.97$ & 0.023 & 1.16 & $0.94-1.43$ & n.s. \\
\hline Other sports/recreation & 0.77 & $0.63-0.94$ & 0.010 & 0.79 & $0.63-0.98$ & 0.032 \\
\hline Other causes & 0.89 & $0.64-1.24$ & n.s. & 0.61 & $0.40-0.94$ & 0.024 \\
\hline \multicolumn{7}{|c|}{$\begin{array}{l}\text { Surgical factors } \\
\text { Days between injury and primary } \\
\text { ACLR }\end{array}$} \\
\hline $0-90$ & 3.07 & $2.44-3.85$ & $<0.001$ & 2.13 & $1.64-2.78$ & $<0.001$ \\
\hline $91-365$ & 1.51 & $1.24-1.83$ & $<0.001$ & 1.55 & $1.26-1.90$ & $<0.001$ \\
\hline >365 Reference group & 1 & & & 1 & & \\
\hline
\end{tabular}

$A C L R$ anterior cruciate ligament reconstruction, $H R$ hazard ratio, $C I$ confidence interval 